\title{
Association between COVID-19 Pandemic and Serious Mental Illness: Rapid Systematic Review within Salutogenesis Model for Public Health Management
}

\author{
Sweta Kaman $^{1}$, Ankita Sharma ${ }^{2}$ and Romi Banerjee ${ }^{3}$ \\ ${ }^{1} \mathrm{PhD}$ Scholar, Department of Science of Intelligence, Indian Institute of Technology Jodhpur, Rajasthan, \\ India, kaman.1@iitj.ac.in, Orcid ID: 0000-0002-3263-8282 \\ ${ }^{2}$ Associate Professor(Psychology), Department of Humanities and Social Sciences, Indian Institute of \\ Technology Jodhpur, Rajasthan, India, ankitasharma@iitj.ac.in, Orcid ID: 0000-0002-1171-838X \\ ${ }^{3}$ Assistant Professor, Department of Computer Science and Engineering, Indian Institute of Technology \\ Jodhpur, Rajasthan, India, romibanerjee@iitj.ac.in, Orcid ID: 0000-0001-6416-6438
}

Corresponding Author: Sweta Kaman, kaman.1@iitj.ac.in

\begin{abstract}
The outburst of the COVID-19 pandemic, constant transformation of the SARS-COV-2 virus form, exposure to substantial psychosocial stress, environmental change, and isolation, has led to the inference that the overall population's mental health could be affected, resulting in an increase in cases of psychosis. Intuitively, patients dealing with Serious Mental Illness (SMI), such as Schizophrenia Spectrum Disorder, Autism Spectrum Disorder, Major Depression, etc., would be particularly susceptible. Existing literature illustrates psychological distress as one of the primary effects of the pandemic amongst people with or without SMI. We initiated a rapid review to determine the impact of the SARS-COV-2 virus and its longterm effects - in both symptomatic and asymptomatic cases - on people with or without psychosis. We envisioned that this would give us an insight into effective clinical intervention methods for patients with psychosis during and after the pandemic. We selected fifteen papers that met our inclusion criteria, i.e., the ones that considered participants with or without psychiatric illness and who had been exposed to SARS-COV-2 infection, for this review. These articles were retrieved via Google, Google Scholar, MEDLINE, PubMed, and PsychINFO Database. Insights from the systematic review have been reviewed from the perspective of the Salutogenesis model. Suggestions and recommendations are made for preventive and promotive public health strategies.
\end{abstract}

\section{Keywords}

COVID-19, Serious Mental Illness (SMI), Salutogenesis Model, Sense of Coherence (SOC), Public Health Management

\section{INTRODUCTION}

We recently witnessed a new variant strain of COVID-19 in England in December 2020. It has been observed that this new strain, i.e., COVID-20 strain, consists of complex mutations [43]. It has also been observed that the COVID-20 strain, which has its origin in low-temperature regions, is more dominant than the COVID-19 strain and younger people are more vulnerable to it [43]. In the wake of the new strain and second wave of COVID-19, it is evident that the end of the pandemic is distant, despite the development of vaccines. We learned $[54,56,57]$ that pandemics are linked with increased risk of mental disorder development and poor mental health. 
From the public health perspective, the COVID-19 pandemic challenges us to prevent mental disorders, protect people with mental disorders from COVID-19, improve mental well-being across populations, and provide public health intervention. These challenges are even more complicated [45] as an evidencebased public health intervention due to inadequacy of the intervention's population coverage even before COVID-19, despite $20 \%$ of the global disease burden being attributable to mental disorders [45]. The COVID-19 has disrupted mental health services, more so in lower-income and middle-income countries (LMICs). [49] commented that mental health as a sustainable development goal was challenging even before the pandemic. It is now highly taxing in LMICs due to fragile and fragmented care systems [52].

To address shortages in service delivery, the 2018 Lancet Commission on global mental health and sustainable development [52] identified mental health as an essential component of universal health coverage. The recent pulse survey (WHO Mental Health Atlas 2017) by WHO on continuity of essential health services during the pandemic provides insights and perspectives on its impact on mental health. However, the pulse survey has its limitations, as only $37 \%$ of the member states regularly compile mental health-specific data (WHO Mental Health Atlas 2017) [67]. Additionally, 29\% of WHO member states compile mental health data as part of general health statistics [21]. As per the pulse report (WHO Mental Health Atlas 2017), lower-income countries have mental health services as part of their national COVID19 response plan, but the level of funding of such plans, whether total or partial, is more significant for higher-income groups. During the COVID-19 pandemic, and at a time when mental, neurological, and substance use (MNS) services are needed on a large scale, many countries are dealing with challenges induced by scarce pre-existing resources and consequent urgent investment in this area [21]. [47] commented that it is crucial to identify strategies to strengthen health systems to overcome these challenges. This can be done by embedding mental health management as part of the core extensive health system.

Two successful global mental health strategies are relevant here. The first is task shifting - training lay health workers to deliver health care in non-specialist settings. The second strategy is the use of digital health technology to strengthen health systems. Task shifting can address the urgent need to build a healthcare provider based in developing countries. This flexible workforce can provide services at the community level, within homes, schools, workplaces, and care centers [48]. There are reports of civil societies setting up teleconsultation for emergencies in low-resource countries like India; however, there is much scope for improvement. While task shifting would provide immediate care, new digital solutions must be developed in alignment with the changing paradigm of mental health care delivery [53]. Identification of risk factors that are particularly relevant to precipitating mental disorders in the face of this pandemic should be explored. The development and implementation of scalable interventions should be done across different communities and different settings to mitigate the infection's impact on mental health.

The mental health consequences of the COVID pandemic can be seen at the primary, secondary, and tertiary levels, which are elucidated in the following subsections:

\section{Primary}

COVID-19 pandemic is correlated to mental and neurological complications, such as stroke, delirium/encephalopathy, agitation, insomnia, loss of taste and smell, anxiety, depression, guillain-barré syndrome $[54,55,56]$, etc. There are some reports of psychotic symptoms described in COVID-19 affected patients $[54,56]$ and some neurological symptoms [57]. In addition to the social consequences of COVID-19, the viruses can also induce neurotoxicity and lead to permanent damage to the central nervous system [58, 59]. Although causality is difficult to establish, the 1918 Spanish influenza coincided with a significant increase in Post-encephalitic Parkinsonism incidence [60]. Preliminary data suggest that one-third of patients hospitalized with COVID-19 have neurological manifestations of this disease [61]. 


\section{Secondary}

Since this virus has constantly been modifying its form [50], we need to be extremely cautious about its secondary effects on people's well-being and possible future health issues. According to specific reports, the COVID-19 pandemic has shown a psychological impact on the general population [62], on patients with SARS-COV-2 infection, and also on healthcare workers [63]. The two previous coronavirus versions like SARS-CoV and Human coronavirus HCoV NL63 in the year 2003-2004 [71], are known to have shown their psychological impact on coronavirus affected patients arising from clinical treatments, exposure to the virus, and psychosocial stress [50]. There would be no surprise if SARS-COV-2 and the newly originated COVID-20 strain led to the same. Despite the disruption to healthcare infrastructure and social support, the potential neuropsychiatric harms of the SARS-COV-2 virus, and past data indicating heightened vulnerability, there is little published data that report on mental health functioning among individuals with pre-existing psychiatric conditions during the current pandemic [51].

\section{Tertiary}

According to some experimental reports [50], it has been observed that both the COVID-19 infected and uninfected people have shown some fear responses, which has caused an unfortunate rise in their psychopathological levels. Psychological intervention is required to treat such cases.

Holmes and colleagues [51] suggested that in non-clinical populations, many factors have affected the mental health issues directly or indirectly and even had unfortunate outcomes of mental health. In his systematic review, [50] attempted evaluation of the impact of pandemics on mental health outcomes for people with mental disorders and Covid associated neuropsychiatric manifestation in these patients. They also observed that most of the reviews published on mental health consequences of COVID-19 - till July 2020 - were reported in the general population [64,65] or studies that examined persons with psychosis and excluded participants with other mental disorders [41]. They also observed that the neuropsychiatric manifestations of pathogens are a generally understudied topic.

The public mental health interventions can be categorized at three levels in the same way that we categorize mental health consequences, which are:

- Primary: Addresses exacerbated risk factors

- Secondary: Early intervention for mental disorders and their associated effects

- Tertiary: Intervention for individuals with an established mental disorder to prevent associated consequences and disability through treatment, patient education, and addressing associate factors

Following the brief background described above, the aim of the present review is 'to analyze the associativity between COVID-19 and mental health consequences through the public health intervention perspective'. The crucial concerns that we will explore in this review include - a) the possible psychological impact of the SARS-CoV-2 virus in both asymptomatic and symptomatic cases, to understand how this will exacerbate current SMI cases and its effect on symptomatology and treatment processes, and b) the presence or absence of primary/secondary/tertiary categories for classification of patients, based on their psychotic symptoms with or without SARS-COV-2 infection, which will help us provide categorical clinical attention to patients, during and after the pandemic. There are systematic reviews with similar intent published in 2020 [46, 50, 47]. However, our rapid review serves three purposes: 1) it supplements other systematic reviews by integrating studies of 'all' empirical articles published in the year 2020;2) it summarizes public mental health improvement suggestions in the pandemic context and; 3 ) it suggests broadening public health intervention mechanisms through Positive Psychology Intervention (PPI), with a shred of evidence collected during the pandemic. 


\section{OBJECTIVES}

Social distancing, lockdown measures, and various other rules circulated by authorities to combat the COVID-19 pandemic can have a lasting impact on people with serious mental illness [41] and the general public. All non-government services and social \& health care services need to be aware of the effects of the COVID-19 pandemic on their services and mechanisms to overcome them to treat and support people with SMI [41]. According to the World Health Organization, informative summaries on issues related to the COVID-19 pandemic and the retrieval of rapid reviews play a vital role in the development of assistive solutions [42]. The present systematic review aims to contribute to the same thorough evaluation of evidence of the impact of the COVID-19 pandemic on people with SMI and non-psychiatric populations from the public health perspective. To bring about this objective, the following are some research questions related to COVID-19 and SMI, which we framed to guide the present review:

1. Can SARS-COV-2 induce SMI in psychiatric as well as non-psychiatric populations?

2. Who, among "the patients having a history of psychosis" and "the patients without prior history of psychosis", are at higher risk of getting affected by severe SARS-COV-2 infection?

3. What are the long-term effects of COVID-19 on people with SMI?

4. Can COVID-19 infected people be categorized into primary/secondary/tertiary levels based on their symptoms and COVID-19 status?

5. What does COVID-19 status inform us, with regards to public health intervention, in the purview of the salutogenesis health model?

Section I presents our systematic review and results from empirical papers on COVID-19 with or without a focus on SMI, while Section II highlights our suggestions and their implications on public health from the perspective of the salutogenesis health model.

\section{SECTION ONE}

This section explains our insights following a rapid systematic review of empirical articles on the COVID-19 pandemic on people with SMI and non-psychiatric populations.

\section{METHODOLOGY}

\section{Inclusion and Exclusion Criteria}

We included studies that reported primary research that 1) included participants with or without psychiatric illness during COVID-19 pandemic or having SMI like schizophrenia, bipolar disorder, etc., or 2) included subjects who had been exposed to SARS-COV-2 infection with or without any family history of psychiatric illness. Our review's exclusion criteria are 1) publications not available in English; 2) unavailability of full text; 3 ) do not show any impact of COVID-19 on mental health.

\section{Search Strategy}

The current article is a systematic review of the existing literature on the impact of the COVID-19 pandemic on patients' mental health with or without SARS-CoV-2 infection. We searched four databases (MEDLINE, PsychINFO, PubMed, Google Scholar) with keywords relating to "COVID-19", "anxiety", "Serious mental illness", "mental health", and "psychosis". Papers published in the year 2020 were selected for our review. A total of thirty articles were selected for the full-text screening, and after a careful review, only fifteen articles were found relevant to the subject of our review and met our inclusion criteria. These studies used the Snowball Sampling Technique, and their samples were limited to a small subgroup of the entire population. 
We also identified some relevant publications $[69,70]$ in Google Scholar, which consisted of keywords relating to "COVID-19", "Work-Life Balance", and "Life Satisfaction", and "Resilience", which we have not included in our review. However, these can be further studied to explore if COVID-19 has brought some changes in our attitude towards life.

\section{Quality Assessment}

After the final selection of articles, the included studies' quality was assessed using the Effective Public Health Practice Project Quality Assessment Tool (EPHPP) [40]. This tool was developed by Ciliska, Miccuci, Dobbins, and Thomas. They led the Effective Public Healthcare Panacea Project (EPHPP) with the support of the Ontario Ministry of Health in Canada in early 1988. This tool effortlessly tests and supports the research and inventions related to public health. It facilitates the rating of a paper's quality as a function of six different components: selection bias, study design, confounders, blinding, data collection method, and withdrawals and dropouts. Each of these individual component ratings is used to derive the final global rating. There are three categories for the global rating, namely: Strong, Moderate, and Weak. If none of the components have a weak rating, then we select "Strong" as our final global rating. If there is only one weak rating, then we select "Moderate" as the global rating. Furthermore, if there are two or more weak ratings, then we select "Weak." The quality assessment results of the selected articles by the EPHPP tool are depicted in table 1. Seven (out of fifteen) included papers received the global rating of 'Strong', four papers (out of fifteen) received 'Moderate', and four (out of fifteen) of 'Weak.'

Table 1. Quality Assessment Global Rating of Included Studies.

\begin{tabular}{|c|c|c|c|c|c|c|c|}
\hline Authors & $\begin{array}{l}\text { Selection } \\
\text { Bias }\end{array}$ & $\begin{array}{l}\text { Study } \\
\text { Design }\end{array}$ & Confounders & Blinding & $\begin{array}{c}\text { Data Collection } \\
\text { Method }\end{array}$ & $\begin{array}{l}\text { Withdrawals } \\
\text { and Dropouts }\end{array}$ & $\begin{array}{l}\text { Global } \\
\text { Rating }\end{array}$ \\
\hline Rohde et al.(2020) & Moderate & Strong & Strong & Strong & Moderate & Moderate & Strong \\
\hline Iasevoli et al.(2020) & Strong & Strong & Strong & Weak & Strong & Strong & Moderate \\
\hline Hao et al.(2020) & Strong & Strong & Strong & Strong & Strong & Moderate & Strong \\
\hline Liu et al.(2020) & Moderate & Moderate & Strong & Weak & Strong & Strong & Moderate \\
\hline Parra et al.(2020) & Strong & Moderate & Strong & Strong & Strong & Moderate & Strong \\
\hline Ferrando et al.(2020) & Weak & Moderate & Moderate & Weak & Strong & Moderate & Weak \\
\hline Smith et al.(2020) & Weak & Moderate & Moderate & Weak & Strong & Moderate & Weak \\
\hline $\begin{array}{c}\text { Varatharaj et } \\
\text { al.(2020) }\end{array}$ & Strong & Strong & Strong & Strong & Strong & Strong & Strong \\
\hline $\begin{array}{c}\text { Valdés-Florido et } \\
\text { al.(2020) }\end{array}$ & Weak & Moderate & Strong & Weak & Strong & Moderate & Weak \\
\hline Fischer et al.(2020) & Weak & Moderate & Moderate & Weak & Moderate & Moderate & Weak \\
\hline Marton et al.(2020) & Strong & Strong & Strong & Weak & Strong & Strong & Moderate \\
\hline Caci et al.(2020) & Strong & Strong & Moderate & Strong & Strong & Strong & Strong \\
\hline $\begin{array}{c}\text { Balsamo and } \\
\text { Carlucci (2020) }\end{array}$ & Strong & Strong & Strong & Strong & Strong & Moderate & Strong \\
\hline Ye et al.(2020) & Strong & Strong & Strong & Strong & Strong & Strong & Strong \\
\hline Sharma et al.(2020) & Moderate & Moderate & Strong & Weak & Moderate & Moderate & Moderate \\
\hline
\end{tabular}

\section{Overview of Included Studies}

The studies included in this review are heterogeneous in design. An overview of included studies is provided in Table 2. A total of fifteen studies were included, which comprises:

- Five cross-sectional analytic studies $[1,4,12,13,14]$,

- Two case reports [7, 10],

- Two case series [6,9],

- Two retrospective studies $[2,5]$,

- A service evaluation [3], 
- A surveillance study [8],

- One observational study [11], and

- One qualitative study [15].

The selected papers describe studies conducted in eight countries: Italy, Denmark, China, Spain, the USA, United Kingdom, Germany, India. One study [2] recruited hospitalized patients with schizophrenia with or without suspected COVID-19 in Hubei Province (China), five studies [5, 6, 7, 8, 15] recruited people with and without psychiatric illness who were confirmed with COVID-19. Furthermore, nine studies [3, $4,1,9,10,11,12,13,14]$ included people with and without psychiatric illness who did not have any SARS-COV-2 infection. One study [14] observed medical and non-medical students. The sample sizes ranged from 1 to 3,675 .

Across all studies, only one study [8] used the CoroNerve study platform. One study [2] reported psychiatric medication use, eight studies $[4,2,5,6,10,12,13,14]$ used clinician-rated scales, and two studies $[1,11]$ used self-rated scales. All the outcomes were primarily psychiatric, including stress, anxiety, depression, sleep quality, and symptoms of psychosis.

\section{STUDY PARTICIPANTS}

As per the inclusion criteria, five different classes of target population were selected, which are illustrated in the Venn diagram in Figure 1.

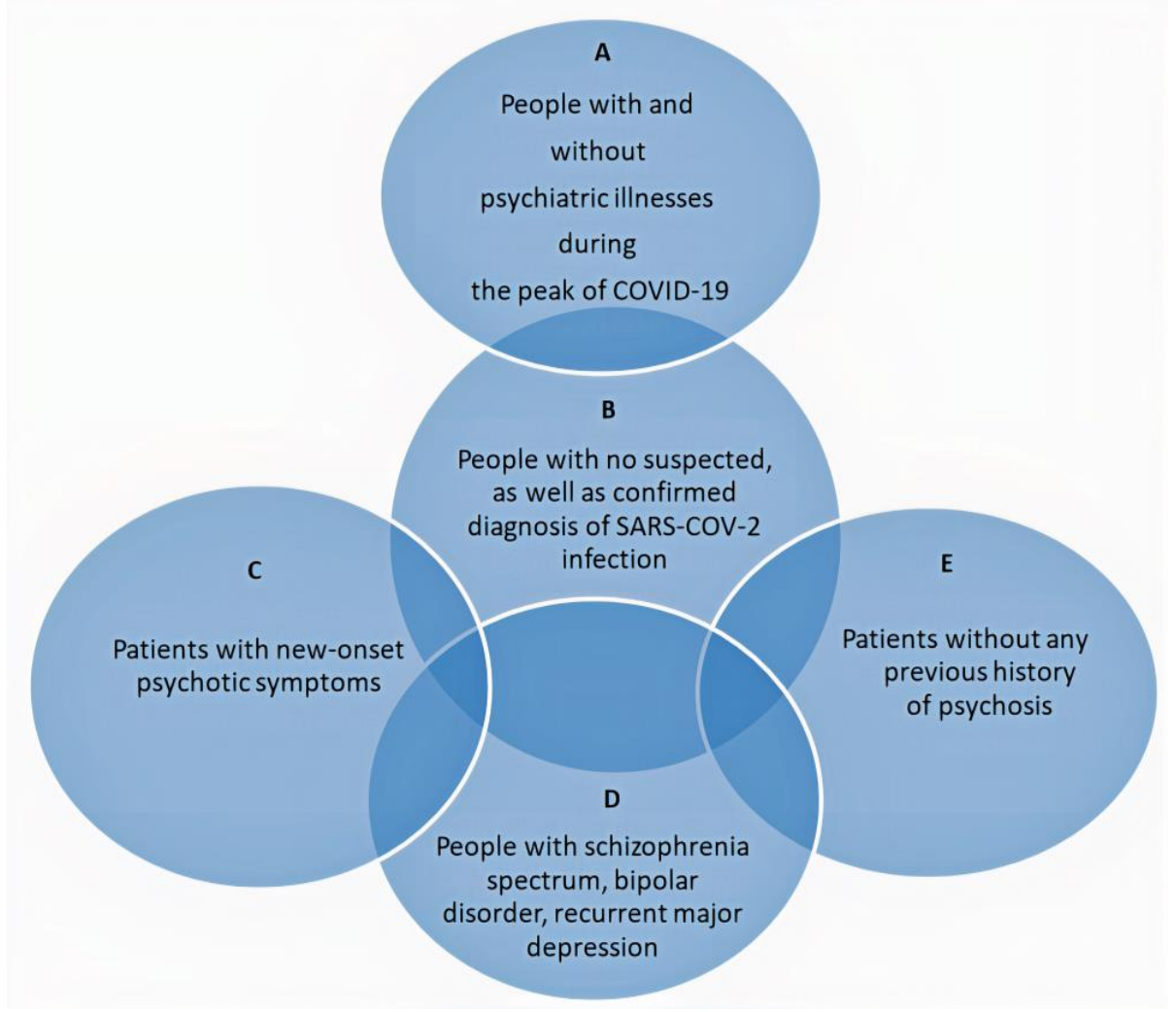

Figure 1. (A) People with and without psychiatric illnesses during the peak of COVID-19; (B) People with schizophrenia spectrum, bipolar disorder, recurrent major depression; (C) People with no suspected, as well as confirmed diagnosis of SARS-COV-2 infection; (D) Patients with new-onset psychotic symptoms, and (E) Patients without any previous history of psychosis. 
Among the selected fifteen studies, six of them $[3,5,6,7,8,15]$ specifically included participants with COVID-19 confirmed cases, and one study [2] included COVID-19 suspected patients. The rest of the eight studies $[4,1,9,10,11,12,13,14]$ recruited individuals having no COVID-19 infection.

\section{STUDY MEASURES}

Some of the most common tools used for the assessment of symptoms and more specifically to detect stress, depression, and cognition level mentioned in the included studies during the COVID-19 phase are as follows:

- $\quad$ The 10-item Perceived Stress Scale (PSS) [22],

- $\quad$ Patient Health Questionnaire (PHQ-9) [24],

- Specific Psychotic Experience Questionnaire (SPEQ) [25],

- Event Scale-Revised (IES-R) [26],

- Depression, Anxiety and Stress Scale (DASS-21) [27],

- Insomnia Severity Index (ISI) [28],

- Positive and Negative Syndrome Scale (PANSS) [29],

- Hamilton Anxiety Rating Scale (HAMA) [30],

- Hamilton Depression Rating Scale (HAMD) [31],

- Pittsburgh Sleep Quality Index (PSQI) [32],

- The 21-item Teate Depression Inventor [33],

- State-Trait Inventory for Cognitive and Somatic Anxiety (STICSA) [34],

- 26-item The Multidimensional State Boredom Scale [35],

- 7-item The Fear of COVID-19 (FCV-19S) [36],

- 8-item The Fantasy Engagement Scale [37],

- The Wisconsin Card Sorting Test [39],

- 5-item General Health Questionnaire (GHQ 12),

- Generalized Anxiety Disorder Scale (GAD-7) [23], and

- Visual Analog Scale [38]

\section{RESULTS}

The inclusion and exclusion criteria and process of paper selection for our review are shown in Figure 2. (following PRISMA method). The initial records identified through the database search were 625, and 10 additional records were searched through other sources. Out of 635 papers, 300 were removed due to duplicity, and 335 were moved forward for screening. 270 papers were removed due to insufficient details, and out of the remaining 65 papers, 30 were shortlisted for the full-text screening. Out of 30, only 15 met our inclusion criteria (refer to figure 2) and were included in the review. The attributes of the included studies are shown in Table 2. The included studies were published in the year 2020 and were undertaken across eight countries: Italy, Denmark, China, Spain, the USA, United Kingdom, Germany, and India. These include a Service Evaluation, five Cross-Sectional Analytic, two Retrospective Studies, two Case Series, two Case Reports, one Surveillance Study, one Observational Study, and one Qualitative Study. 


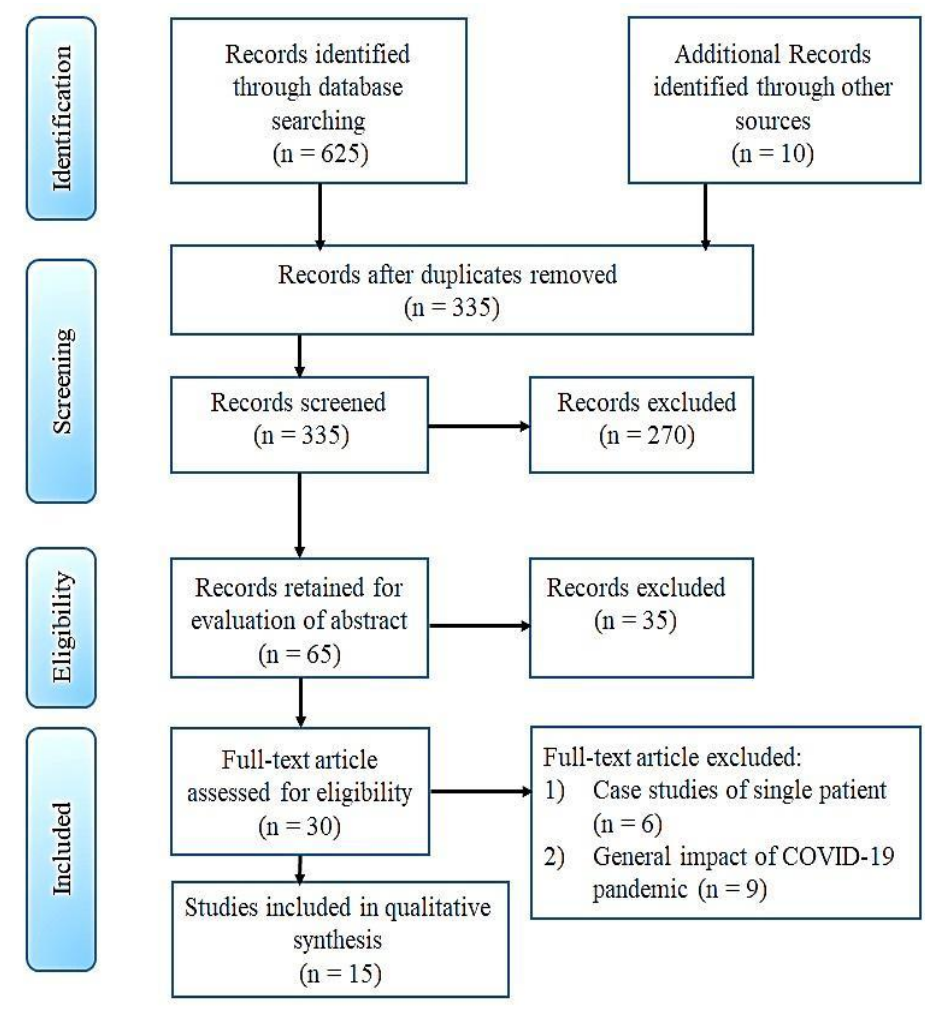

\begin{tabular}{|l|}
\hline Inclusion Criteria: \\
- \\
withdies on the general population \\
illnesses during the peak of \\
COVID-19, \\
People with schizophrenia \\
spectrum, bipolar disorder, \\
recurrent major depression, \\
People with no suspected, as \\
well as confirmed diagnosis of \\
SARS-CoV-2 infection, \\
Patients with new-onset \\
psychotic symptoms, and, \\
Patients without any previous \\
history of psychosis were \\
selected as the target population. \\
- \\
Publications not available in \\
English, \\
Articles with no full text, and \\
Articles which do not show any \\
impact of COVID-19 on mental \\
health.
\end{tabular}

Figure 2. PRISMA Flow Diagram

\section{Observational studies on the mental health status of people with SMI due to COVID- 19}

We identified four papers $[3,4,2,6]$ that present a direct association (primary associativity) between the COVID-19 virus and psychosis. These include a Service Evaluation [3], a Cross-Sectional Analytic [4], a Retrospective Study [5], and a Case Series [6]. Additionally, we identified three papers that illustrate that people with SMI are at higher risk of getting affected by severe SARS-COV-2 infection. These consist of a Cross-Sectional Analytic [1], a Retrospective Study [2]), and a Case Report [10]. The severity of COVID-19 in these studies ranged from mild to extreme.

In the Cross-Sectional Analytic by [4], patients with Serious Mental Illness were studied. It has been found that these patients demonstrated a higher risk of getting depressed and are more likely to get COVID-19 related stress and anxiety than non-psychiatric people. Such individuals have been shown to have three times higher risk of getting distressed, severe depression, and anxiety symptoms due to the COVID-19 pandemic compared to the general population. The factors which lead to the heightened risk of severe anxiety in patients having SMI are: 1) higher susceptibility towards medical disorders; 2) stress due to lockdown restrictions; 3) their own mental illness; 4) stress perceived due to the outbreak of COVID-19 pandemic; and 5) uncertain economic status [4]. This article enforces the need to focus on patients' mental health with SMI and the general population, given that the effects of the COVID-19 pandemic directly affect their sanity [4].

In a Case Series by [6], the authors identified an association between the COVID-19 pandemic and a new-onset psychosis. The presence of multiple psychological and stress-related factors causing psychosis in COVID-19 confirmed patients were found. In the first case, they studied a 30-year-old male without 
any prior history of psychosis but with panic disorder. Before he was presented to the emergency department (ED), the symptoms he demonstrated were suicidal ideation, extreme anxiety, auditory hallucination, suspiciousness, the delusion of people chasing him, sleep disorder, calling himself by a wrong name, etc. He was later tested COVID-19 positive and transferred to the medical service for further treatment. In the second case, they studied a 34-year-old unmarried female who had known exposure to COVID-19 with a prior history of panic disorder and anxiety. When she came for the ED evaluation, she had symptoms like agitation, inattentiveness, pressure, suspicion, and delusions regarding some fire burning inside the room, tingling sensation, and numbness in the body. According to the family, she never had shown any of these symptoms before, but of late. She, too, was found COVID-19 positive and was administered doses of Aripiprazole and Lorazepam, which are used to treat schizophrenia, bipolar disorder, and depressive disorder, respectively. When she showed some improvement, she was transferred to the medical service for further COVID-19 and antipsychotic medication. In the third case, a COVID-19 positive 33-year-old male was studied who was having delusions and hallucinations regarding his ex-wife, had no previous history of psychosis, and his mini cognition examination was routine as well. He was given quetiapine daily for COVID-19 treatment to be later transferred to the psychiatric unit [6]. This study also states that if there is a relationship between the COVID-19 pandemic and the new-onset psychosis, the general treatment of psychosis is likely to be affected by treatments for SARS-COV-2 infection. This makes it very clear that COVID-19 affects the recovery process in the treatment of people with psychosis.

In a Retrospective study by [2], they primarily targeted the clinical features of schizophrenic patients having COVID-19 infection. A comparison was made between the inpatient Schizophrenia patients with and without suspected COVID-19 infection. The clinical features of Schizophrenia patients with COVID19 suspected infection are stress, mood swings, anxiety, and disturbances in sleeping patterns [2]. These patients also had a higher mean Hamilton Depression Rating Score (HAMD) [31], Pittsburgh Sleep Quality Index Score (PSQI) [32]), Perceived Stress Score (PSS) [22], and Hamilton Anxiety Rating Scale score (HAMA) [30] in comparison to the Schizophrenia patients without COVID-19 infection [2]. This highlights that a combination of psychosis and COVID-19 can worsen a patient's condition. On the other hand, psychosis without COVID-19 infection does not show the worst mental health symptoms. The design-risk and selection-bias in this study are shown in Table 1, and a weak rating for the blinding processes inherently implies a higher risk of observer bias. For this study, a separate isolation ward was a handy setup for treating people with psychosis to reduce the virus's spread (Secondary associativity).

Some papers $[1,20,68]$ have listed socioeconomic impacts (the rising trajectory of suicide) of COVID-19 in Canada, the USA, Pakistan, India, France, Germany, and Italy. These papers are not part of our systematic review as they do not directly deal with mental health issues in the context of COVID-19.

\section{Observational studies on the mental health status of non-psychiatric people due to COVID-19}

We identified five papers that address the incident cases of psychosis on non-psychiatric people due to COVID-19. These include one case report [7], one case series [9], one observational study [11], one cross-sectional analytic [13], and one qualitative study [15].

In a case series by [9], non-COVID-19 positive patients aged 18-65 were studied. In the first case of the series, a 33-year-old male, admitted with psychotic symptoms and suicidal behavior, without any prior personal and family history of psychosis, was studied. He demonstrated symptoms of paranoid psychosis and believed that the world was coming to an end due to the massive control of machines over humans and that he would lose his job because of the COVID-19 crisis. His psychotic symptoms disappeared when he was treated with olanzapine. In the second case, a 43-year-old female was studied with no prior history of psychosis but a prior history of BPD episodes. She was admitted under the COVID-19 related new psychotic relapse. She demonstrated symptoms like disorganized speech, weird behavior, had delusions regarding her family being affected by the COVID-19 infection, etc. Her condition improved to a reasonable extent with medication. In the third case, a 32-year-old female without any prior history of psychosis was studied. She was admitted to the hospital due to new-onset psychosis related to the 
COVID-19 crisis. She continuously believed that she is an asymptomatic carrier of COVID-19 infection and could affect others and had delusions of her close ones dying due to the COVID-19 crisis. In the fourth case, a 45-year-old male was studied with no prior personal and family history of psychosis. He was admitted to the hospital due to suicidal tendencies arising from psychosis. He was distressed with the increasing death rates due to the COVID-19 crisis and checked the death toll obsessively. He also started having delusions similar to schizophrenic symptoms like hearing his neighbors' voices and believed that Illuminati controls the COVID-19 pandemic. After being treated with daily medication, his psychotic condition remitted within 72 hours.

In a Cross-Sectional Analytic by [13], quarantined Italian adults aged 18 and older were studied. People who were less worried about the COVID-19 pandemic, especially students, females, and young people, were likely to acquire a higher risk of getting depression. They also identified that generic levels of symptoms related to depression did not develop into a higher likelihood of getting infected. These findings also suggest that to have future insights on implementing psychological interventions, we need to identify groups with a higher risk of psychosis due to the COVID-19 pandemic by monitoring all psychological outcomes (tertiary associativity).

In a Qualitative Study by [15], an interview-based semi-structured qualitative analysis was conducted on 59 participants. Out of 59 participants, two were found to be COVID-19 positive. Three factors affecting the Indian population psychologically during COVID-19 were identified: Information, Isolation, and Misinfodemics. It was raised that anxiety, knowledge, and a neutral approach in India are led by the flow of information. Isolation was observed to drive the Indian population towards psychological strength like cognitive dissonance and adaptability rather than depression. More attention is needed to prevent misinfodemics and ensuing panic resulting from fake news during the pandemic [15]. This is the only Indian study we could find within our inclusion criteria.

According to the above studies, an increase in the number of brief reactive psychotic disorders can be witnessed due to the COVID-19 pandemic. High risks of suicidal ideation - characterize psychosis caused by the COVID-19 pandemic, and short-lived psychotic recurrence has low diagnostic stability over time. Close monitoring of both acute phase and long-term follow-up of such patients should be done. The mandatory nationwide quarantine enforced during COVID-19 by the authorities constitutes a higher risk factor for developing reactive psychosis. Patients with reactive psychosis tend to be emotionally reactive and vulnerable to impulsive behavior (tertiary associativity).

\section{DISCUSSION}

\section{Key Gaps}

Studies by $[1,4,9,10,11,12,13,14,15]$ have analyzed the non-COVID-19 infected population. [5, 6, 7, $8]$ have analyzed the COVID-19 infected population. [1, 4, 9, 10] have shown the impact of the COVID19 pandemic on non-COVID-19 infected people with psychosis. [11] and [14] have presented the impact of COVID-19 on non-COVID-19 infected people without any prior personal history of psychosis. Authors of $[5,6,8]$ in their studies have highlighted the impact of the COVID-19 pandemic on the mental health of COVID-19 infected people already having psychosis. [7] and [8] have shown the impact of COVID-19 on the mental health of COVID-19 infected people - without any prior personal history of psychosis.

Forty-three percent of the included studies have attempted to understand the impact on the mental health of people with SMI or mental disorders and psychiatric symptoms during the COVID-19 crisis. Thirty-six percent of the included reviewed studies have tried to understand the impact on people's mental health without any prior personal history of psychosis during the COVID-19 outbreak. Twenty-one percent of the studies included have tried to comprehend the impact of new-onset psychosis on patients with and without COVID-19 infection. 
However, there is a dearth of evidence and research on the question - "Does the presence of SARS-COV2 virus, in both psychiatric and non-psychiatric people, affect their mental health, for cases of symptomatic and asymptomatic COVID-19?". An in-depth study and understanding of how COVID-19 affects people with or without a prior personal history of psychosis, and people with symptomatic or asymptomatic COVID-19, will confirm if there exists a direct link or any primary associativity between the SARS-COV-2 virus and psychosis. This will ultimately lead to answers to multiple queries directly or indirectly related to this above-said query: a) Will the medications be different in both symptomatic and asymptomatic COVID-19? b) Will the treatment process be affected due to the presence of the SARSCOV-2 virus and psychosis at the same time in a person?

We did not find sufficient proof of the claim that COVID-19 infection directly causes SMI. More experiments, reviews, and surveys need to be inducted in the COVID-19 positive population to understand the relationship between COVID-19 and SMI. There is also the utmost need to comprehend the borderline between the pattern of psychosis among symptomatic and asymptomatic patients and between people with or without a prior personal history of psychosis. All of the included studies focus on how the general population's mental health and people with SMI are affected during the COVID-19 pandemic within a fixed time-bound. There is a lack of proper categorization of psychotic patients with or without SARS-COV-2 infection.

Based on the symptoms of psychosis in a patient and their COVID-19 status, we can categorize them into three groups. First is the primary group where we can cluster the patients with psychosis which is directly caused due to the SARS-COV-2 infection. The second would be a secondary group, where we categorize the patients whose symptoms of psychosis are not caused directly due to SARS-COV-2 infection but as a consequence of the symptoms of COVID-19 infection. The third category is the tertiary group in which patients' mental health is affected due to social consequences of COVID-19 infection like social isolation, anger, fear, etc.

These categories will help us significantly address the precise clinical needs of patients with psychosis during and after the times of pandemic. Considering this, the present study provides initial proof for how people with or without psychosis are affected due to the COVID-19 pandemic, in both symptomatic and asymptomatic cases. This also presents a futuristic outlook of the pandemic, given the constant transformation in its form shown by the virus. 
Table 2. Attributes of Included Studies.

\begin{tabular}{|c|c|c|c|c|c|c|}
\hline Author & $\begin{array}{l}\text { Time of Data } \\
\text { Collection \& } \\
\text { Origin }\end{array}$ & Study Design & Population(s) Studied & $\begin{array}{l}\text { COVID-19 } \\
\text { Status }\end{array}$ & Tools \& Measures & Findings \\
\hline $\begin{array}{l}\text { Liu et al. } \\
\text { (2020) }\end{array}$ & $\begin{array}{l}\text { January 30- } \\
\text { February 21, } \\
2020 \\
\text { (China) }\end{array}$ & $\begin{array}{l}\text { Retrospective } \\
\text { studies }\end{array}$ & $\begin{array}{l}\text { People with suspected coviD- } \\
19 \text { \& Schizophrenia; } \\
\text { (n=51) }\end{array}$ & $\begin{array}{l}\text { Suspected COVID- } \\
19\end{array}$ & $\begin{array}{l}\text { Positive \&Negative Affect Schedule } \\
\text { (PANAS), PSS, HAMA, HAMD, PSQII }\end{array}$ & $\begin{array}{l}\text {-Targeted identifying clinical features of schizophrenic patients having COVID-19 infection. } \\
\text {-Clinical features are stress, mood swings, \& disturbances in sleeping patterns. }\end{array}$ \\
\hline $\begin{array}{l}\text { Hao et al. } \\
\text { (2020) }\end{array}$ & $\begin{array}{l}\text { February 19- } \\
22,2020 \\
\text { (China) }\end{array}$ & $\begin{array}{l}\text { Cross-Sectional } \\
\text { analytic }\end{array}$ & $\begin{array}{l}\text { People with \& without } \\
\text { psychosis during strict COVID-19 } \\
\text { lockdown measures; } \\
(\mathrm{n}=185)\end{array}$ & $\begin{array}{l}\text { No Covid-19 } \\
\text { infection }\end{array}$ & $\begin{array}{l}\text { Event Scale-Revised (IES-R), } \\
\text { Depression, Anxiety \& Stress Scale } \\
\text { (DASS-21), \& Insomnia Severity Index } \\
\text { (ISI) }\end{array}$ & $\begin{array}{l}\text {-Patients with psychosis are at higher risk of getting high levels of stress, anxiety, depression, } \\
\text { PTSD, insomnia. } \\
\text {-Psychiatric patients may also encounter worries about their physical health, suicidal ideation, } \\
\text { irritability, \& anger compared to healthy controls. }\end{array}$ \\
\hline $\begin{array}{l}\text { Rohde et } \\
\text { al. (2020) }\end{array}$ & $\begin{array}{l}\text { February 1- } \\
\text { March 23, } 2020 \\
\text { (Denmark) }\end{array}$ & Service Evaluation & $\begin{array}{l}\text { The general population with } \\
\text { mental illness aged } 18 \text { or above; } \\
(n=918)\end{array}$ & Status Unknown & $\begin{array}{l}\text { Electronic medical record system } \\
\text { used by the psychiatric services of } \\
\text { the Central Denmark Region (CDR). }\end{array}$ & $\begin{array}{l}\text {-1357 clinical notes from } 918 \text { retrieved describing COVID-19 pandemic-related psychiatric } \\
\text { symptoms. } \\
\text {-Cumulative incidence of patients with pandemic-related psychopathology } \\
\text {-Clear association between no. of COVID-19 cases \& degree of Pandemic-related } \\
\text { psychopathology. }\end{array}$ \\
\hline $\begin{array}{l}\text { Ye et al. } \\
\text { (2020) }\end{array}$ & $\begin{array}{l}\text { March 5-10, } \\
2020 \\
\text { (China) }\end{array}$ & $\begin{array}{l}\text { Cross-Sectional } \\
\text { analytic }\end{array}$ & $\begin{array}{l}\text { Medical students as well as } \\
\text { non-medical students; aged } \\
16 \sim 31 \text { years old; } \\
\mathrm{n}=3675\end{array}$ & $\begin{array}{l}\text { No Covid-19 } \\
\text { infection }\end{array}$ & $\begin{array}{l}\text { Chinese Perceived Stress Scales } \\
\text { (CPSS) }\end{array}$ & $\begin{array}{l}\text {-Medical students have higher stress as compared to non-medical students } \\
\text {-Risk factors due to which medical students are affected by psychological stress are: 1) lower } \\
\text { family income; 2) aging; 3) less familiar with COVID-19; \& 4) intern student }\end{array}$ \\
\hline $\begin{array}{l}\text { Valdés- } \\
\text { Florido et } \\
\text { al., (2020) }\end{array}$ & $\begin{array}{l}\text { March 14- 28, } \\
2020 \\
\text { (Spain) }\end{array}$ & Case Series & $\begin{array}{l}\text { Patients with reactive psychoses } \\
\text { related to COVID-19; } \\
(n=4)\end{array}$ & $\begin{array}{l}\text { No Covid-19 } \\
\text { infection }\end{array}$ & $\begin{array}{l}\text { DSM-5; } \\
\text { Case Report (CARE) guidelines }\end{array}$ & $\begin{array}{l}\text {-An increase in the number of brief reactive psychotic disorders witnessed due to COVID-19 } \\
\text { Pandemic. } \\
\text {-Psychosis caused by COVID-19 Pandemic has a high risk of suicidal ideation, psychotic } \\
\text { recurrence is short-lived, \& has low diagnostic stability over time. } \\
\text {-Patients with reactive psychosis tend to be emotionally reactive \& vulnerable to impulsive } \\
\text { behavior. }\end{array}$ \\
\hline $\begin{array}{l}\text { Fischer et } \\
\text { al. (2020) }\end{array}$ & $\begin{array}{l}\text { March 17, } 2020 \\
\text { (Germany) }\end{array}$ & Case report & $\begin{array}{l}\text { A 43-year-old male patient } \\
\text { suffering from schizophrenia } \\
\text { psychosis; } \\
(n=1)\end{array}$ & $\begin{array}{l}\text { No Covid-19 } \\
\text { infection }\end{array}$ & $\begin{array}{l}\text { Positive \& Negative Syndrome } \\
\text { Scale(PANSS); The Wisconsin Card } \\
\text { Sorting Test }\end{array}$ & $\begin{array}{l}\text {-lllustrates patients' psychopathology with paranoid psychosis being severely affected by the } \\
\text { COVID-19 Pandemic. } \\
\text {-COVID-19 pandemic resulted in outbreak of a psychotic phase. } \\
\text {-Patient had psychosis, but occurrence of COVID-19 made it worse, due to which patient started } \\
\text { having paranoid-hallucinatory experiences. } \\
\text {-Report illustrates possibility of COVID-19 induced psychosis. }\end{array}$ \\
\hline $\begin{array}{l}\text { Balsamo, } \\
\text { M., \& } \\
\text { Carlucci, L., } \\
\text { (2020) }\end{array}$ & $\begin{array}{l}\text { March 21-26, } \\
2020 \\
\text { (Italy) }\end{array}$ & $\begin{array}{l}\text { Cross-Sectional } \\
\text { analytic }\end{array}$ & $\begin{array}{l}\text { Italian quarantined adults aged } \\
18 \& \text { older; } \\
(\mathrm{n}=3,672)\end{array}$ & $\begin{array}{l}\text { No CoVID-19 } \\
\text { infection }\end{array}$ & $\begin{array}{l}\text { 21-item Teate Depression Inventor; } \\
\text { 21-item state scale of the State-Trait } \\
\text { Inventory for Cognitive \& Somatic } \\
\text { Anxiety (STICSA); }\end{array}$ & $\begin{array}{l}\text {-Generic symptom levels of depression did not induce higher likelihood of getting infected. } \\
\text {-People have a higher risk of getting depression who were not much worried about the COVID- } \\
19 \text { Pandemic. }\end{array}$ \\
\hline $\begin{array}{l}\text { lasevoli et } \\
\text { al. (2020) }\end{array}$ & $\begin{array}{l}\text { April 13-17, } \\
2020 \text { (Italy) }\end{array}$ & $\begin{array}{l}\text { Cross-Sectional } \\
\text { analytic }\end{array}$ & $\begin{array}{l}\text { People with schizophrenia } \\
\text { spectrum, bipolar disorder, } \\
\text { recurrent major depression; } \\
\text { ( } \mathrm{n}=461)\end{array}$ & $\begin{array}{l}\text { No covid-19 } \\
\text { infection }\end{array}$ & $\begin{array}{l}\text { Perceived Stress Scale (PSS), } \\
\text { Generalized Anxiety Disorder Scale } \\
\text { (GAD-7), Patient Health } \\
\text { Questionnaire (PHQ-9), \& Specific } \\
\text { Psychotic Experience Questionnaire } \\
\text { (SPEQ), Paranoia subscale }\end{array}$ & $\begin{array}{l}\text {-Patients with SMI showed a higher risk of getting depressed \& are more likely to get COVID-19 } \\
\text { related stress \& anxiety than non-psychiatric people. } \\
\text {-The factors leading to the heightened risk of severe anxiety are: } 1 \text { ) higher susceptibility of the } \\
\text { patients with SMI towards medical disorders; 2) stress due to lockdown restrictions; 3) own } \\
\text { mental illness; 4) stress perceived due to outbreak of COVID-19 Pandemic; \& 5) uncertain } \\
\text { economic status. }\end{array}$ \\
\hline
\end{tabular}


Table 2. Attributes of Included Studies (Contd.)

\begin{tabular}{|c|c|c|c|c|c|c|}
\hline $\begin{array}{l}\text { Parra et al. } \\
\text { (2020) }\end{array}$ & $\begin{array}{l}\text { March-April } \\
2020 \\
\text { (Spain) }\end{array}$ & $\begin{array}{l}\text { Retrospective } \\
\text { studies }\end{array}$ & $\begin{array}{l}\text { Patients with new-onset } \\
\text { psychotic symptoms \& } \\
\text { confirmed diagnosis of SARS- } \\
\text { COV-2 infection (by real-time } \\
\text { PCR) aged } 18 \text { or above; } \\
(\mathrm{n}=10)\end{array}$ & $\begin{array}{l}\text { COVID-19 } \\
\text { confirmed } \\
\text { (Symptomatic) }\end{array}$ & $\begin{array}{l}\text { Delirium Rating Scale-Revised- } \\
98 \text { (DRS-98, Spanish version) } \\
\text { (Fonseca et al., 2005) \& clinical notes }\end{array}$ & $\begin{array}{l}\text {-Confusions' \& 'structured delusions' were identified as the most frequent manifestations. } \\
\text {-Direct effect on mental health could be due to a direct attack on the CNS. } \\
\text {-Indirect effect could be caused by hypoxia, inflammatory reactions, disturbances in metabolism } \\
\text { rate, etc. \& pharmacological side-effects of treatments. }\end{array}$ \\
\hline $\begin{array}{l}\text { Marton et } \\
\text { al. (2020) }\end{array}$ & $\begin{array}{l}\text { March 24- May } \\
13,2020 \\
\text { (Italy) }\end{array}$ & $\begin{array}{l}\text { Observational } \\
\text { study }\end{array}$ & $\begin{array}{l}\text { Italian Health Care Workers } \\
\text { working during the COVID-19 } \\
\text { Pandemic }(n=458)\end{array}$ & $\begin{array}{l}\text { No CovID-19 } \\
\text { infection }\end{array}$ & $\begin{array}{l}\text { General Health Questionnaire - } 12 \\
\text { (GHQ-12) \& Visual Analog Scale }\end{array}$ & $\begin{array}{l}\text {-Posttraumatic stress disorder (PTSD) is emerging as the primary cause of burnout among Italian } \\
\text { Health Care Workers (HCWs). } \\
\text {-Factor that associates workers' primary emotions with their cognition is perception of 'lack of } \\
\text { control'. } \\
\text {-Factors affecting mental health of HCWs are loneliness, anger, fear for their own family \& the } \\
\text { patients, perceived lack of control. }\end{array}$ \\
\hline $\begin{array}{l}\text { Varatharaj } \\
\text { et al. } \\
(2020)\end{array}$ & $\begin{array}{l}\text { April 2-26, } 2020 \\
\text { (United } \\
\text { Kingdom) }\end{array}$ & Surveillance study & $\begin{array}{l}\text { General patients with COVID19 } \\
\text { reported across the UK; } \\
\text { (n=153) }\end{array}$ & $\begin{array}{l}\text { COVID-19 } \\
\text { confirmed }\end{array}$ & $\begin{array}{l}\text { Coro Nerve study platforms, ABN } \\
\text { portal, BASP portal, RC Psych portal }\end{array}$ & $\begin{array}{l}\text {-Clinicians \& patients with COVID-19 having Cerebrovascular events \& altered mental status } \\
\text { were identified as a significant proportion within the cohort. } \\
\text {-An increase in the cases of "acute alteration in mental status" was identified, consisting of } \\
\text { psychotic symptoms \& neurological syndromic diagnosis. }\end{array}$ \\
\hline $\begin{array}{l}\text { Caci et al. } \\
\text { (2020) }\end{array}$ & $\begin{array}{l}\text { May 7-18, } 2020 \\
\text { (Italy) }\end{array}$ & $\begin{array}{l}\text { Cross-Sectional } \\
\text { analytic }\end{array}$ & $\begin{array}{l}\text { People aged between } 18 \& 57 \\
\text { years, mainly women; } \\
(\mathrm{n}=301)\end{array}$ & $\begin{array}{l}\text { No Covid-19 } \\
\text { infection }\end{array}$ & $\begin{array}{l}\text { 20-item Personality Inventory; 26- } \\
\text { item Multidimensional State } \\
\text { Boredom Scale; 7-item Fear of } \\
\text { COVID-19 (FCV-19S; 8-item Fantasy } \\
\text { Engagement Scale; } \\
\text { 5-item Time Management Behavior } \\
\text { Scale }\end{array}$ & $\begin{array}{l}\text {-Results suggest that highly neurotic people are more likely to have higher emotional reactivity; } \\
\text { such people lack resources to manage stress levels. }\end{array}$ \\
\hline $\begin{array}{l}\text { Ferrando et } \\
\text { al. (2020) }\end{array}$ & $\begin{array}{l}\text { New York, } \\
\text { USA }\end{array}$ & Case Series & $\begin{array}{l}\text { Asymptomatic COVID-19 } \\
\text { patients having physical } \\
\text { symptoms but with new-onset } \\
\text { psychotic symptoms ; }(n=3)\end{array}$ & $\begin{array}{l}\text { COVID-19 } \\
\text { Confirmed } \\
\text { (Asymptomatic) }\end{array}$ & $\begin{array}{l}\text { Chest x-ray \& brain computed } \\
\text { tomography (CT) scan, Sequential } \\
\text { Organ Failure Assessment score, CRP, } \\
\text { etc. }\end{array}$ & $\begin{array}{l}\text {-Identified association between COVID-19 Pandemic \& new-onset psychosis. } \\
\text {-Presence of multiple psychological \& stress-related factors causing psychosis in COVID-19 } \\
\text { confirmed patients were found. }\end{array}$ \\
\hline $\begin{array}{l}\text { Smith et al. } \\
(2020)\end{array}$ & (USA) & Case report & $\begin{array}{l}\text { A 36-year-old lady with no prior } \\
\text { personal or family history of } \\
\text { mental illness, } \\
(\mathrm{n}=1)\end{array}$ & $\begin{array}{l}\text { COVID-19 } \\
\text { confirmed } \\
\text { (Symptomatic) }\end{array}$ & $\begin{array}{l}\text { Bedside tests of attention, } \\
\text { concentration, orientation, CT scan, } \\
\text { MRI, meningitis PCR panel, etc. }\end{array}$ & $\begin{array}{l}\text {-In this case report, no family or personal history of psychosis \& no previous prodromal } \\
\text { symptoms are identified. } \\
\text {-The patient encountered upper respiratory symptoms on the onset of psychosis. }\end{array}$ \\
\hline $\begin{array}{l}\text { Sharma et } \\
\text { al. (2020) }\end{array}$ & (India) & Qualitative study & $\begin{array}{l}\text { General Population; } \\
(n=59)\end{array}$ & $\begin{array}{l}97 \% \text { of target } \\
\text { population had } \\
\text { no COVID-19 } \\
\text { infection }\end{array}$ & $\begin{array}{l}\text { Semi-structured interview; } \\
\text { Consolidated criteria for reporting } \\
\text { qualitative research (COREQ) } \\
\text { guidelines }\end{array}$ & $\begin{array}{l}\text { - Identified three factors affecting the Indian population during COVID-19, which are: } \\
\text { Information, Isolation, \& Misinfodemics } \\
\text {-Anxiety, knowledge, \&a neutral approach in India are led by the flow of information. } \\
\text { - Isolation is observed to drive the Indian population towards psychological strength like } \\
\text { cognitive dissonance \&adaptability rather than depression. }\end{array}$ \\
\hline
\end{tabular}




\section{SECTION TWO}

The following section presents suggestions emerging from the studies analyzed in the previous section and extends that within the salutogenesis model with a public health perspective.

\section{Suggestions and Recommendation from Empirical Articles:}

Mental health is already an integral part of the UN's sustainable development goals' health and wellbeing-related goal. The WHO health system strengthening frames and mental health action plan 20132020 is also based on the objective of 'build back better'. The realization of limitations in the availability of mental health services has led to many initiatives from governments and funding bodies. It is imperative to understand and analyze the neurological correlations and behavioral expressions related to the mental health consequences of COVID-19, within intersections of age, gender, migrants, health workers, and disadvantaged groups. It is also pertinent to gather data regarding immediate psychosocial problems, effects of socioeconomic policies, and possible stigma and discrimination in help-seeking. The National Academy of Sciences also suggested having person-centered care, shared decision-making and patient and family engagement, and making mental health an integral part of the management of COVID 19 [44].

Some of the articles analyzed in the previous section also provide insightful suggestions from their work perspective. [1] suggested that the awareness regarding the requirement of care with continuous psychiatric intervention given to psychiatric patients should be very high during the COVID-19 pandemic. As [9] found, patients with reactive psychosis tend to be emotionally reactive and vulnerable to impulsive behavior; and due to the mandatory nationwide quarantine enforced during COVID-19, the authorities constitute a higher risk factor for developing reactive psychosis. A separate isolation ward is a handy set up for treating people with psychosis to reduce the virus's spread. Additionally, close monitoring of both acute phase and long-term follow-up of these types of patients should be done [2].

We cannot entirely ignore the possibility of young peoples' mental health being affected due to the current pandemic situation. Similarly, medical students' stress levels need to be decreased timely to maintain a positive professional and learning attitude during the times of the COVID-19 pandemic [14]. [12] recommended that to modulate the anxiety level due to the fear of the COVID-19 pandemic and improve individuals' psychological well-being, we need to be aware of the various psychological treatment programs. To have a future insight into implementing psychological interventions, we can identify groups having a higher risk of psychosis due to the COVID-19 pandemic by monitoring all psychological outcomes [13].

Both Fischer and colleagues [10] and Sharma and colleague [15] suggested monitored media use in pandemic and epidemics situations. To reduce the risk of over reactiveness among the people with SMI, the media should take responsibility to show measured and balanced reporting regarding the COVID-19 pandemic. Furthermore, a lot more attention is needed towards the misinfodemics by policymakers, resulting from fake news, to avoid panic during the pandemic phase.

A holistic approach is required for handling a problem like a pandemic, leading to issues at multiple levels. An integral part as an acknowledgment to COVID-19 pandemic should be public mental health practices, which ultimately leads to a legacy and immediate positive effects to outlast the pandemic long. It can only be done if service providers develop community-based models, focus on training and upskilling primary health workers and non-mental health professionals. This will also help address the disruption of health-related services, as is evident in WHO's pulse report (WHO Mental Health Atlas 2017), where severe disruption has been found for MNS-related services in participating countries. Otherwise, globally, only a minority of individuals with mental disorders receive any treatment, coverage of interventions to prevent associated effects is all the more flawed, and coverage of interventions to prevent mental disorders or promote mental well-being is negligible [19]. 
The salutogenesis model by Antonovsky (1987) provides an excellent holistic framework to look at the health and public mental health intervention, not only for the prevention of mental illness but also for promoting mental well-being.

\section{Salutogenesis Model of Health}

In the 1970s, a medical sociologist, Aron Antonovsky (1987), asked what makes people healthy? This question and subsequent research by Antonovske and others led to a significant change in health research. Antonovsky (1987) gave the salutogenesis model of health a more holistic view of health. Traditionally biomedical models and public mental health hold different focuses (river metaphor) [refer to Figure 3]. In contrast, the biomedical model focuses on the cure or treatment of disease and health protection, and the public mental health focuses on disease prevention, health education, and health promotion.

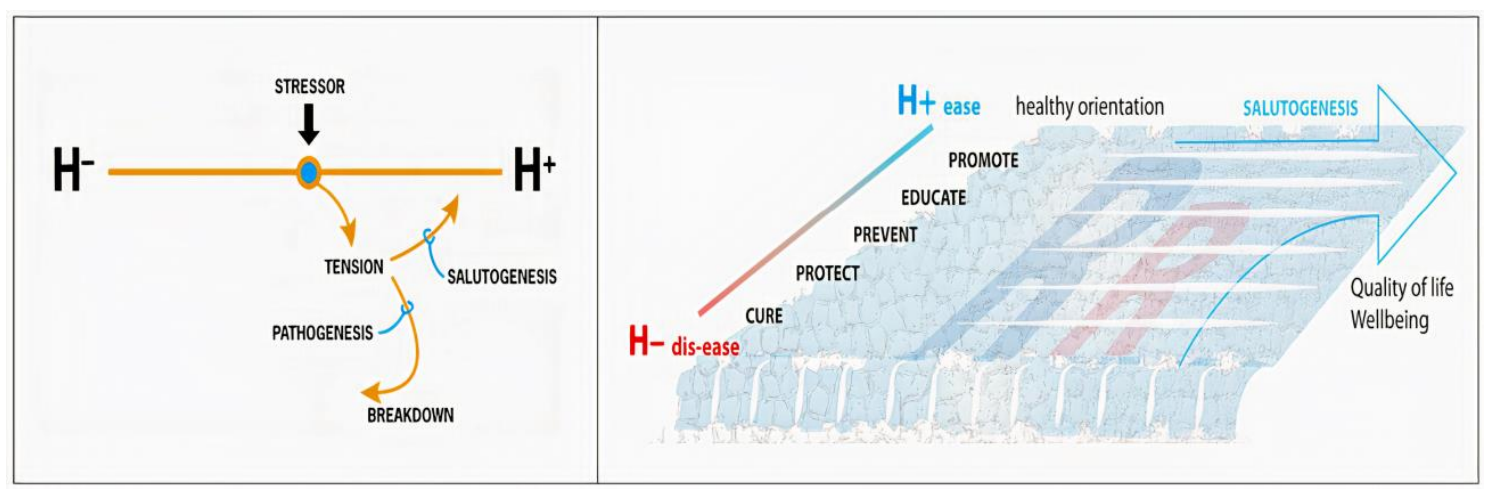

Figure 3. Antonovsky's explanation of the health continuum and the Salutogenic direction (to the left) and The River of Life (Right). Note the vertical right-hand flow in the direction of life towards well-being and Quality of life. The image depicts Antonovsky's health continuum H- to H+, R stands for Risk and Resource. [66]

The salutogenesis model provides a holistic perspective on health in the current approach, and the Positive Psychology Intervention (PPI) is described in the following section.

\section{Positive Psychology Intervention}

Positive Psychology is a branch, and Positive Psychology Intervention (PPI) is a relatively recent development. In its six years of publication of the Handbook of Positive Psychological Intervention (2014), PPI has gained much interest across healthcare communities. In 2020 a special edition on PPI published the Journal of Positive Psychology. These special issues provide recent trends in the field. The editors of this issue, [18], commented that PPI research over-focuses on well-being and depression, leading under exploration of other variables. The editors' suggestion was to conduct more studies in a real-world setting on diverse populations and examine novel approaches like digital delivery of PPIs.

Combining the PPI and salutogenesis model of health gives a broader outlook on health and provides preventive and promotive intervention. We found two such articles Schafer and colleagues [72] and [17], which explored the sense of coherence (SOC) as a buffer of resistance factors to stress response in light of the pandemic. Antonovsky situated Salutogenesis as a question on the origins of health, and his answer was the sense of coherence. Schafer and colleagues [72] did a prospective study and analyzed the relation of SOC and psychopathological symptoms (pre-post outbreak) in Germany. They found that small groups of participants from the total sample size $(\mathrm{n}=1591)$ with low SOC levels experienced increased psychopathological symptoms. 
However, most of the participants reported stable mental health. The positive link between SOC and health is well documented; however, the possible moderating role is unclear. [17], therefore, explicitly examined the extent of SOC moderation in the well-being and COVID-19 illness experience (fear to contract and people diagnosed with COVID-19) in 2784 participants in Italy. The finding backed the abating role of SOC. People with low SOC levels and who knew at least one COVID-19 patient showed a lower level of well-being. However, the negative relationship of well-being and fear of reducing COVID19 was more robust for high SOC people. [16] have suggested that the SOC's buffer ability may depend on the health indicators considered and the type and severity of stress. Though this study has its limitations, and we have only these two studies explicitly exploring the role of SOC as a stress buffer, these results provide new possibilities. Identifying such positive qualities that act as a buffer and designing PPIs may lead to potential preventive strategies.

\section{CONCLUSION AND FUTURE DIRECTION}

The main finding from our rapid review is that we do not have sufficient evidence to prove that COVID19 infection directly causes SMI. Extensive experiments, reviews, and surveys are required within the COVID-19 positive population to understand the relationship between COVID-19 and SMI. There is moderate evidence of new-onset psychosis during the COVID-19 phase in which some antipsychotics treated the patients. There is also low-to-moderate evidence of patients already having a history of psychosis who are COVID-19 positive. These show no conclusive evidence regarding which group among the 'patients already having a history of psychosis' and the 'patients without any prior history of psychosis' are more vulnerable to the psychological effects of the SARS-COV-2 virus, that would ultimately prove whether COVID-19 does indeed induce SMI if it affects the second group. There is no evidence for the categorization of people with psychosis into primary/secondary/tertiary classes based on their psychotic symptoms and their COVID-19 status (positive/negative) in both conditions of symptomaticity and asymptomaticity, which will motivate us to answer the question "Does COVID-19 directly induce SMI?". Based on the current literature, our review highlights that significantly less consideration has been given to the population with SMI. There is also the utmost requirement to understand the borderline between the pattern, and such classification is envisioned to assist in the appropriate clinical intervention for symptomatic and asymptomatic patients with or without a prior personal history of psychosis during and after the pandemic. However, we have sufficient evidence to see the association between COVID-19 and mental health conditions, which poses public health management challenges. The current pandemic has disrupted the delivery of essential and MNS services, especially for vulnerable populations. There is a strong need to think of a strategy to prepare our system for combating such a situation. The Salutogenesis model and PPIs provide another approach for preventive and promotive public health management.

\section{Consent for Publication}

Not applicable.

\section{Standard of Reporting}

PRISMA guidelines have been followed for this study.

\section{Declaration of Conflicting Interests}

The author(s) declared no potential conflicts of interest.

\section{Funding}

The author(s) received no financial support for the research, authorship, and publication of this article. 


\section{References}

[1] Hao, F., Tan, W., Jiang, L., Zhang, L., Zhao, X., Zou, Y., Hu, Y., Luo, X., Jiang, X., McIntyre, R. S., Tran, B., Sun, J., Zhang, Z., Ho, R., Ho, C., \& Tam, W. (2020). Do psychiatric patients experience more psychiatric symptoms during COVID-19 pandemic and lockdown? A case-control study with service and research implications for immunopsychiatry. Brain, Behavior, and Immunity, 87(April), 100-106. https://doi.org/10.1016/j.bbi.2020.04.069

[2] Liu, X., Lin, H., Jiang, H., Li, R., Zhong, N., Su, H., Li, Y., \& Zhao, M. (2020). Clinical characteristics of hospitalised patients with schizophrenia who were suspected to have coronavirus disease (COVID-19) in Hubei Province, China. General Psychiatry, 33(2), 1-7. https://doi.org/10.1136/gpsych-2020-100222

[3] Rohde, C., Jefsen, O. H., Nørremark, B., Danielsen, A. A., \& Østergaard, S. D. (2020). Psychiatric Symptoms Related to the COVID-19 Pandemic. MedRxiv. https://doi.org/10.1101/2020.04.16.20067744

[4] Iasevoli, F., Fornaro, M., D'Urso, G., Galletta, D., Casella, C., Paternoster, M., ... \& COVID-19 in Psychiatry Study Group. (2020). Psychological distress in serious mental illness patients during the COVID-19 outbreak and one-month mass quarantine in Italy. Psychological Medicine, 1-6.

[5] Parra, A., Juanes, A., Losada, C. P., Álvarez-Sesmero, S., Santana, V. D., Martí, I., ... \& Rentero, D. (2020). Psychotic symptoms in COVID-19 patients. A retrospective descriptive study. Psychiatry Research, 291, 113254.

[6] Ferrando, S. J., Klepacz, L., Lynch, S., Tavakkoli, M., Dornbush, R., Baharani, R., ... \& Bartell, A. (2020). COVID-19 psychosis: a potential new neuropsychiatric condition triggered by novel coronavirus infection and the inflammatory response?. Psychosomatics. https://doi.org/10.1016/j.psym.2020.05.012

[7] Smith, C. M., Komisar, J. R., Mourad, A., \& Kincaid, B. R. (2020). COVID-19-associated brief psychotic disorder. BMJ Case Reports CP, 13(8), e236940.

[8] Varatharaj, A., Thomas, N., Ellul, M. A., Davies, N. W., Pollak, T. A., Tenorio, E. L., ... \& Coles, J. P. (2020). Neurological and neuropsychiatric complications of COVID-19 in 153 patients: a UKwide surveillance study. The Lancet Psychiatry, 7(10), 875-882.

[9] Valdés-Florido, M. J., López-Díaz, Á., Palermo-Zeballos, F. J., Martínez-Molina, I., Martín-Gil, V. E., Crespo-Facorro, B., \& Ruiz-Veguilla, M. (2020). Reactive psychoses in the context of the COVID-19 pandemic: clinical perspectives from a case series. Revista de Psiquiatría y Salud Mental (English Edition), 13(2), 90-94.

[10] Fischer, M., Coogan, A. N., Faltraco, F., \& Thome, J. (2020). COVID-19 paranoia in a patient suffering from schizophrenic psychosis-a case report. Psychiatry Research, 288, 113001.

[11] Marton, G., Vergani, L., Mazzocco, K., Garassino, M. C., \& Pravettoni, G. (2020). 2020s Heroes Are Not Fearless: The Impact of the COVID-19 Pandemic on Wellbeing and Emotions of Italian Health Care Workers During Italy Phase 1. Frontiers in Psychology, 11, 2781.

[12] Caci, B., Miceli, S., Scrima, F., \& Cardaci, M. (2020). Neuroticism and Fear of COVID-19. The Interplay Between Boredom, Fantasy Engagement, and Perceived Control Over Time. Frontiers in Psychology, 11, 2578.

[13] Balsamo, M., \& Carlucci, L. (2020). Italians on the Age of COVID-19: The Self-Reported Depressive Symptoms Through Web-Based Survey. Frontiers in Psychology, 11.

[14] Ye, W., Ye, X., Liu, Y., Liu, Q., Vafaei, S., Gao, Y., ... \& Zhan, C. (2020). Effect of the novel coronavirus pneumonia pandemic on medical students' psychological stress and its influencing factors. Frontiers in Psychology, 11.

[15] Sharma, G. D., Ghura, A. S., Mahendru, M., Erkut, B., Kaur, T., \& Bedi, D. (2020). Panic during COVID-19 Pandemic! A qualitative investigation into the psychosocial experiences of a sample of Indian people. Frontiers in Psychology, 11, 2494.

[16] Quehenberger, V., \& Krajic, K. (2017). Applications of salutogenesis to aged and highly-aged persons: residential care and community settings. The Handbook of Salutogenesis, 325-335.

[17] Barni D, Danioni F, Canzi E, Ferrari L, Ranieri S, Lanz M, Iafrate R, Regalia C and Rosnati R (2020) Facing the COVID-19 Pandemic: The Role of Sense of Coherence. Frontiers in Psychology, 11:578440. doi: 10.3389/fpsyg.2020.578440 
[18] Acacia C. Parks \& Eliane M. Boucher (2020). Positive Psychological Interventions (PPIs) in the age of COVID-19: on the potential impact of digital PPIs on loneliness, The Journal of Positive Psychology, 15:5, 569-571, DOI: 10.1080/17439760.2020.1789715

[19] Kola L. (2020). Global mental health and COVID-19. The Lancet. Psychiatry, 7(8), 655-657. https://doi.org/10.1016/S2215-0366(20)30235-2

[20] Thakur V, Jain A. COVID 2019-suicides: A global psychological pandemic. Brain, behavior, and immunity. 2020 Aug 1.

[21] Clinical management of COVID-19: interim guidance. Geneva: World Health Organization; 2020 (https://www.who.int/publications/i/item/clinical-management-of-covid-19, accessed October 2 2020)

[22] Cohen, S., Kamarck, T., \& Mermelstein, R. (1994). Perceived stress scale. Measuring Stress: A Guide for Health and Social Scientists, 10, 1-2.

[23] Spitzer, R. L., Kroenke, K., Williams, J. B., \& Löwe, B. (2006). A brief measure for assessing generalized anxiety disorder: the GAD-7. Archives of Internal Medicine, 166(10), 1092-1097.

[24] Löwe, B., Kroenke, K., Herzog, W., \& Gräfe, K. (2004). Measuring depression outcome with a brief self-report instrument: sensitivity to change of the Patient Health Questionnaire (PHQ-9). Journal of Affective Disorders, 81(1), 61-66.

[25] Ronald, A., Sieradzka, D., Cardno, A. G., Haworth, C. M., McGuire, P., \& Freeman, D. (2014). Characterization of psychotic experiences in adolescence using the specific psychotic experiences questionnaire: findings from a study of 5000 16-year-old twins. Schizophrenia Bulletin, 40(4), 868877.

[26] Christianson, S., \& Marren, J. (2012). The impact of event scale-revised (IES-R). Medsurg Nurs, 21(5), 321-322.

[27] Beaufort, I. N., De Weert-Van Oene, G. H., Buwalda, V. A., de Leeuw, J. R. J., \& Goudriaan, A. E. (2017). The depression, anxiety and stress scale (DASS-21) as a screener for depression in substance use disorder inpatients: a pilot study. European Addiction Research, 23(5), 260-268.

[28] Morin, C. M., Belleville, G., Bélanger, L., \& Ivers, H. (2011). The Insomnia Severity Index: psychometric indicators to detect insomnia cases and evaluate treatment response. Sleep, 34(5), 601-608.

[29] Kay, S. R., Fiszbein, A., \& Opler, L. A. (1987). The positive and negative syndrome scale (PANSS) for schizophrenia. Schizophrenia Bulletin, 13(2), 261-276.

[30] Vaccarino, A. L., Evans, K. R., Sills, T. L., \& Kalali, A. H. (2008). Symptoms of anxiety in depression: assessment of item performance of the Hamilton Anxiety Rating Scale in patients with depression. Depression and Anxiety, 25(12), 1006-1013.

[31] Zimmerman, M., Martinez, J. H., Young, D., Chelminski, I., \& Dalrymple, K. (2013). Severity classification on the Hamilton depression rating scale. Journal of Affective Disorders, 150(2), 384388.

[32] Smyth, C. (1999). The Pittsburgh sleep quality index (PSQI). Journal of Gerontological Nursing, 25(12), 10-10.

[33] Balsamo, M., \& Saggino, A. (2014). Determining a diagnostic cut-off on the Teate Depression Inventory. Neuropsychiatric Disease and Treatment, 10, 987.

[34] Ree, M. J., French, D., MacLeod, C., \& Locke, V. (2008). Distinguishing cognitive and somatic dimensions of state and trait anxiety: Development and validation of the State-Trait Inventory for Cognitive and Somatic Anxiety (STICSA). Behavioural and Cognitive Psychotherapy, 36(3), 313.

[35] Fahlman, S. A., Mercer-Lynn, K. B., Flora, D. B., \& Eastwood, J. D. (2013). Development and validation of the multidimensional state boredom scale. Assessment, 20(1), 68-85.

[36] Ahorsu, D. K., Lin, C. Y., Imani, V., Saffari, M., Griffiths, M. D., \& Pakpour, A. H. (2020). The fear of COVID-19 scale: development and initial validation. International journal of mental health and addiction, 1-9.

[37] Plante, C. N., Reysen, S., Groves, C. L., Roberts, S. E., \& Gerbasi, K. (2017). The Fantasy Engagement Scale: A flexible measure of positive and negative fantasy engagement. Basic and Applied Social Psychology, 39(3), 127-152.

[38] Williams, V. S., Morlock, R. J., \& Feltner, D. (2010). Psychometric evaluation of a visual analog scale for the assessment of anxiety. Health and Quality of Life Outcomes, 8(1), 57.

[39] Chelune, G. J., \& Baer, R. A. (1986). Developmental norms for the Wisconsin Card Sorting test. Journal of Clinical and Experimental Neuropsychology, 8(3), 219-228. 
[40] Evans, N., Lasen, M., \& Tsey, K. (2015). Appendix A: Effective public health practice project (EPHPP) quality assessment tool for quantitative studies. A Systematic Review of Rural Development Research. SpringerBriefs in Public Health, 45-55.

[41] Brown, E., Gray, R., Monaco, S. L., O'Donoghue, B., Nelson, B., Thompson, A., Francey, S. \& McGorry, P. (2020). The potential impact of COVID-19 on psychosis: A rapid review of contemporary epidemic and pandemic research. Schizophrenia Research. https://doi.org/10. 1016/j.schres.2020.05.005.

[42] Tricco, A. C., Langlois, E., Straus, S. E., \& World Health Organization. (2017). Rapid reviews to strengthen health policy and systems: a practical guide. World Health Organization.

[43] Estrada, Mario Arturo Ruiz. "CAN WE STOP COVID-19 SHORTLY?." 10.13140/RG.2.2.10420.88968/4

[44] Campion, J., Javed, A., Sartorius, N., \& Marmot, M. (2020). Addressing the public mental health challenge of COVID-19. The Lancet. Psychiatry, 7(8), 657-659. https://doi.org/10.1016/S2215$\underline{0366(20) 30240-6}$

[45] WHO. Global health estimates 2016: disease burden by cause, age, sex, country and region, 20002016.

2018.https://www.who.int/healthinfo/global_burden_disease/estimates/en/index1.html(accessed April 28, 2020).

[46] Xiong, J., Lipsitz, O., Nasri, F., Lui, L., Gill, H., Phan, L., Chen-Li, D., Iacobucci, M., Ho, R., Majeed, A., \& McIntyre, R. S. (2020). Impact of COVID-19 Pandemic on mental health in the general population: A systematic review. Journal of Affective Disorders, 277, 55-64. https://doi.org/10.1016/j.jad.2020.08.001

[47] Maulik, P. K., Thornicroft, G., \& Saxena, S. (2020). Roadmap to strengthen global mental health systems to tackle the impact of the COVID-19 pandemic. International Journal of Mental Health Systems, 14(1), 1-13.

[48] Kohrt, B. A., Asher, L., Bhardwaj, A., Fazel, M., Jordans, M. J., Mutamba, B. B., ... \& Patel, V. (2018). The role of communities in mental health care in low-and middle-income countries: a metareview of components and competencies. International Journal of Environmental Research and Public Health, 15(6), 1279.

[49] Wasserman, I. M. (1992). The impact of epidemic, war, prohibition and media on suicide: United States, 1910-1920. Suicide and Life-Threatening Behavior, 22(2), 240-254.

[50] Sergeant, A., van Reekum, E. A., Sanger, N., Dufort, A., Rosic, T., Sanger, S., ... \& Samaan, Z. (2020). Impact of COVID-19 and other pandemics and epidemics on people with pre-existing mental disorders: a systematic review protocol and suggestions for clinical care. BMJ open, 10(9), e040229. doi:10.1136/ bmjopen-2020-040229

[51] Holmes, E. A., O'Connor, R. C., Perry, V. H., Tracey, I., Wessely, S., Arseneault, L., ... \& Bullmore, E. (2020). Multidisciplinary research priorities for the COVID-19 pandemic: a call for action for mental health science. The Lancet Psychiatry.7:547-60.

[52] Patel, V., Saxena, S., Lund, C., Thornicroft, G., Baingana, F., Bolton, P., ... \& UnÜtzer, J. (2018). The Lancet Commission on global mental health and sustainable development. The Lancet, 392(10157), 1553-1598.

[53] Mahmood, S., Hasan, K., Carras, M. C., \& Labrique, A. (2020). Global preparedness against COVID-19: We must leverage the power of digital health. JMIR Public Health and Surveillance, 6(2), e18980.

[54] Pfefferbaum, B., \& North, C. S. (2020). Mental health and the Covid-19 Pandemic. New England Journal of Medicine, 383(6), 510-512.

[55] Liang, L., Ren, H., Cao, R., Hu, Y., Qin, Z., Li, C., \& Mei, S. (2020). The effect of COVID-19 on youth mental health. Psychiatric Quarterly, 91(3), 841-852.

[56] Ellul, M. A., Benjamin, L., Singh, B., Lant, S., Michael, B. D., Easton, A., ... \& Solomon, T. (2020). Neurological associations of COVID-19. The Lancet Neurology. 19(9):767-83

[57] Anderson, R. M., Heesterbeek, H., Klinkenberg, D., \& Hollingsworth, T. D. (2020). How will country-based mitigation measures influence the course of the COVID-19 epidemic?. The Lancet, 395(10228), 931-934.

[58] Swanson II, P. A., \& McGavern, D. B. (2015). Viral diseases of the central nervous system. Current Opinion in Virology, 11, 44-54. 
[59] Mao, L., Jin, H., Wang, M., Hu, Y., Chen, S., He, Q., ... \& Hu, B. (2020). Neurologic manifestations of hospitalized patients with coronavirus disease 2019 in Wuhan, China. JAMA Neurology, 77(6), 683-690.

[60] McCall, S., Vilensky, J. A., Gilman, S., \& Taubenberger, J. K. (2008). The relationship between encephalitis lethargica and influenza: a critical analysis. Journal of Neurovirology, 14(3), 177-185.

[61] Douglas, P. K., Douglas, D. B., Harrigan, D. C., \& Douglas, K. M. (2009). Preparing for pandemic influenza and its aftermath: mental health issues considered. International Journal of Emergency Mental Health, 11(3), 137.

[62] Troyer, E. A., Kohn, J. N., \& Hong, S. (2020). Are we facing a crashing wave of neuropsychiatric sequelae of COVID-19? Neuropsychiatric symptoms and potential immunologic mechanisms. Brain, Behavior, and Immunity. 87, 34-9.

[63] Wells, G. A., Shea, B., O'Connell, D., Peterson, J., Welch, V., Losos, M., \& Tugwell, T. (2011). The Newcastle-Ottawa scale (NOS) for assessing the quality of nonrandomised studies in metaanalyses. Ottawa: Ottawa Hospital Research http://www.ohri.ca/programs/clinical_epidemiology/oxford.asp

[64] Rajkumar, R. P. (2020). COVID-19 and mental health: A review of the existing literature. Asian Journal of Psychiatry, 52, 102066.

[65] Rogers, J. P., Chesney, E., Oliver, D., Pollak, T. A., McGuire, P., Fusar-Poli, P., ... \& David, A. S. (2020). Psychiatric and neuropsychiatric presentations associated with severe coronavirus infections: a systematic review and meta-analysis with comparison to the COVID-19 pandemic. The Lancet Psychiatry, 7(7), 611-627.

[66] Lindström, B., Eriksson, (2010). The Hitchhiker's Guide to Salutogenesis: Salutogenic Pathways to Health Promotion. Helsinki: Folkhälsan Research Center, Health Promotion Research.

[67] World Health Organization. Mental health action plan 2013-20. Geneva: World Health Organization; 2013.

[68] Mamun MA, Ullah I. COVID-19 suicides in Pakistan, dying off not COVID-19 fear but poverty?The forthcoming economic challenges for a developing country. Brain, behavior, and immunity. 2020 Jul 1.

[69] Satici, S. A., Kayis, A. R., Satici, B., Griffiths, M. D., \& Can, G. (2020). Resilience, Hope, and Subjective Happiness Among the Turkish Population: Fear of COVID-19 as a Mediator. International Journal of Mental Health and Addiction, 1-16.

[70] Lu, H., Nie, P., \& Qian, L. (2020). Do quarantine experiences and attitudes towards COVID-19 affect the distribution of psychological outcomes in China? A quantile regression analysis (No. 512). GLO Discussion Paper.

[71] Galante O, Avni YS, Fuchs L, Ferster OA, Almog Y. Coronavirus NL63-induced Adult Respiratory Distress Syndrome. Am J Respir Crit Care Med. 2015;193: 100-101. pmid:26720790

[72] Schäfer SK, Sopp MR, Schanz CG, Staginnus M, Göritz AS, Michael T. Impact of COVID-19 on public mental health and the buffering effect of a sense of coherence. Psychotherapy and psychosomatics. 2020;89(6):386-92. 